\title{
Rapid and safe discharge from the emergency department: A single troponin to exclude acute myocardial infarction
}

Lisa Brichko (MBBS, DCH, MHM AFRACMA) ${ }^{1}$, Hans G Schneider (MBBS, MD, FRACP, FRCPA) ${ }^{2,3}$, William Chan (MBBS, PhD, FRACP) ${ }^{4,5,6}$, Jarrel Seah (MBBS, BMedSci) ${ }^{1}$, De Villiers Smit (MBChB, FACEM) ${ }^{1,7,8}$, Anthony Dart (BA, BM, BCh, FRACP, FRCP, DPhil) ${ }^{4}$ Jeremy P Stevens (MBBS, FACEM) ${ }^{1}$, Biswadev Mitra (MBBS, MHSM, PhD, FACEM) $)^{1,7,8}$

${ }^{1}$ Emergency \& Trauma Centre, The Alfred Hospital, Melbourne, Victoria, Australia ${ }^{2}$ Clinical Biochemistry Unit, The Alfred Hospital, Melbourne, Victoria, Australia ${ }^{3}$ Central Clinical School, Monash University, Melbourne, Victoria, Australia ${ }^{4}$ Cardiology Department, The Alfred Hospital, Melbourne, Victoria, Australia ${ }^{5}$ Cardiology Department, Western Health, Melbourne, Victoria, Australia ${ }^{6}$ Melbourne Medical School, University of Melbourne, Melbourne, Victoria, Australia

${ }^{7}$ National Trauma Research Institute, The Alfred Hospital, Melbourne, Victoria, Australia

${ }^{8}$ Department of Epidemiology \& Preventive Medicine, Monash University, Melbourne, Victoria, Australia

Word Count: 2497 words

Corresponding Author: Dr Lisa Brichko

L.Brichko@alfred.org.au

This is the author manuscript accepted for publication and has undergone full peer review but has not been through the copyediting, typesetting, pagination and proofreading process, which may lead to differences between this version and the Version of Record. Please cite this article as doi: 10.1111/1742-6723.12919

This article is protected by copyright. All rights reserved. 
Emergency and Trauma Centre, Alfred Hospital, 55 Commercial Road, Melbourne, 3004 Australia.

\begin{abstract}
Objective: To determine variables that could facilitate safe discharge from the Emergency Department (ED) following a single High Sensitivity Troponin I (HsTnI) result to exclude acute myocardial infarction (AMI).

Methods: A retrospective cohort study was performed at a tertiary hospital of all patients that had serial HsTnI performed within 12 hours of arrival to the ED over a 3 year period. The primary exposure variable of interest was a very low troponin initial result $(\mathrm{HsTnI}<5 \mathrm{ng} / \mathrm{L})$. Medical record review and risk stratification score calculations were undertaken for all patients with the exposure variable of interest and an abnormal second troponin measurement (HsTnI e 16ng/L in women and HsTnI e26ng/L in men).

Results: There were 11,970 patients who presented between 01/07/2013 and 30/06/2016 that had serial HsTnI measurements performed. Of these, 4,172 (34.9\%) patients had an initial HsTnI measurement $<5 \mathrm{ng} / \mathrm{L}$. Of the patients with an initial $\mathrm{HsTnI}<5 \mathrm{ng} / \mathrm{L}$ that met inclusion criteria, $56(1.3 \%)$ had a second troponin result above the $99^{\text {th }}$ percentile and $32(0.8 \%)$ cases of NSTEMI were diagnosed as well as $15(0.4 \%)$ cases of STEMI. There were $44(93.6 \%)$ of all AMI cases that met criteria for high risk presentations under the National Heart Foundation of Australia guidelines. The negative predictive value of an initial $\mathrm{HsTnI}<5 \mathrm{ng} / \mathrm{L}$ to exclude AMI was $98.9 \%$ (95\% CI 98.5-99.1).
\end{abstract}

This article is protected by copyright. All rights reserved. 
Conclusions: This supports the utilisation of a rapid rule out strategy to exclude AMI for patients that have an initial $\mathrm{HsTnI}$ measurement $<5 \mathrm{ng} / \mathrm{L}$ in conjunction with a robust risk assessment.

Abstract word count: 243 words

This article is protected by copyright. All rights reserved. 


\section{Introduction}

Chest pain and other symptoms of potential acute coronary syndrome (ACS) account for up to $10 \%$ of Emergency Department (ED) Presentations ${ }^{1}$. The associated annual cost to the Australian healthcare system is estimated to be almost two billion dollars ${ }^{2}$. Rapid and safe exclusion of a diagnosis of acute myocardial infarction (AMI) is of paramount importance to ensure efficient patient care as well as to minimise ED overcrowding and limit healthcare $\operatorname{costs}^{3}$.

The cornerstones of AMI diagnosis have traditionally been built upon patient assessment, electrocardiogram (ECG) interpretation and serial blood testing to assess troponin levels as a biomarker of cardiac myocyte necrosis ${ }^{4,5}$. The vast majority of patients who are investigated with serial troponin measurements will ultimately be found not to have a diagnosis of $\mathrm{AMI}^{6}$. The ability to efficiently discharge patients with a very low probability of AMI after a single troponin measurement remains to be convincingly validated ${ }^{3}$. Utilising a single troponin measurement along with clinical assessment and ECG findings to determine disposition could potentially reduce hospital admissions, decrease ED overcrowding, improve patient care by avoiding unnecessary waiting times and also have economic benefits to the health service ${ }^{7}$.

The advent of high sensitivity troponin assays ( $\mathrm{HsTn}$ ) has propelled the formulation of novel accelerated pathways for assessing patients with suspected AMI. The possibility that these HsTn assays might be able to rule out AMI more efficiently than historical troponin assays, has led to increased attention to potential protocols to rapidly rule out AMI at the time of ED presentation $^{8}$. Very low plasma concentrations of HsTn at presentation have a high negative 
predictive value for $\mathrm{AMI}^{9}$. This has drastically shortened the time interval between serial troponin measurements from up to 12 hours to within 3 hours with HsTn serial testing ${ }^{3}$.

Previous studies of HsTn use to rapidly exclude AMI have been constrained by restrictive patient selection inclusion criteria ${ }^{9,10}$. Other limitations included the reliance on the analysis of frozen and rethawed specimens, tested in a non-clinical setting to obtain later troponin measurements and thereby potentially not capturing the real-time results afforded by fresh specimen analysis ${ }^{8}$.

The aim of this study was to determine, in a clinical setting of a tertiary referral hospital, the performance of a HsTn assay in a real life all comer cohort of consecutive patients presenting to an Australian emergency department. We evaluated the clinical characteristics of patients, who have an initial HsTnI result of less than $5 \mathrm{ng} / \mathrm{L}$ and a subsequent abnormal serial HsTnI measurement. This was intended to describe patients where the diagnosis of AMI could potentially be excluded following a single HsTnI measurement.

\section{Methods}

This single-centre retrospective study was conducted at a tertiary referral teaching hospital (The Alfred Hospital, Melbourne, Australia), serviced by a level 4 emergency department using the Australasian College for Emergency Medicine definition. There are approximately 60,000 annual ED presentations to the Alfred Hospital. Assessment of potential AMI in this setting involves a thorough clinical assessment as well as serial ECG/troponin testing at 0 and 3 hours.

This article is protected by copyright. All rights reserved. 
All patients presenting to the Alfred Hospital ED that underwent at least two troponin measurements within the first $12 \mathrm{hrs}$ after arrival to hospital during the three year period from $1^{\text {st }}$ July 2013 to $30^{\text {th }}$ June 2016 were included in this study. Data were extracted from the Alfred Hospital's REASON Cohort Discovery Tool hospital corporate platform ${ }^{11}$ and included patient age, sex, Australian Triage Scale (ATS) rating, mode of transport to hospital, time of arrival to the ED, times of collection of troponin specimens, troponin results, renal function and ED Length of Stay (LOS).

Patients were excluded if they had been initially seen at another hospital and transferred to the Alfred Hospital as they may have already had troponin measurements performed externally prior to arrival at the Alfred. They were also excluded if they had undergone a surgical intervention (not including percutaneous coronary interventions/coronary artery bypass grafts) prior to their second HsTnI measurement being performed as these patients may have had a perioperative AMI. The Alfred Hospital Trauma Centre routinely performs troponin measurements as part of a standard pathology care set for major trauma presentations to detect cases of cardiac contusion and as such these seriously injured patients were also excluded.

Pathology testing was performed onsite in real-time using the Abbott Architect fifth generation High Sensitivity Troponin I Assay (HsTnI). A very low HsTnI was defined as a HsTnI result of less than $5 \mathrm{ng} / \mathrm{L}$. This assay has a limit of detection of $1.9 \mathrm{ng} / \mathrm{L}$, and a CV of $12.6 \%$ has been reported at $3.5 \mathrm{ng} / \mathrm{L}^{12}$. We used the $99^{\text {th }}$ sex specific percentile of e $16 \mathrm{ng} / \mathrm{L}$ for women and e26ng/L for men which reflects the agreed Australian reference intervals based upon local and international reference data ${ }^{13,14}$. 
The primary exposure variable of interest was an initial very low troponin $(\mathrm{Hs} \operatorname{Tn} \mathrm{I}<5 \mathrm{ng} / \mathrm{L})$ with a subsequent second troponin measurement that was abnormal (defined as e 16ng/L for women or e26ng/L for men). Individual chart review of patients with the exposure variable involved assessment of presenting symptoms, initial ECG interpretation, cardiac risk factors, provocative cardiac stress tests, angiograms, percutaneous coronary interventions (PCI), coronary artery bypass grafts $(\mathrm{CABG})$, and whether antiplatelet/anticoagulant medication was commenced at discharge. Patient cases were reviewed by two investigators independently (LB, WC) to adjudicate whether a myocardial infarction (MI) had occurred according to the Third Universal Definition of Myocardial Infarction ${ }^{15}$. Patient 30 day survival was determined by chart review and through contacting patient's general practitioners. The comparator cohort were patients with an initial troponin $<5 \mathrm{ng} / \mathrm{L}$ with normal second HsTnI measurement. The primary outcome variable of interest was the diagnosis of a Non STElevation MI (NSTEMI) or a diagnosis of ST-elevation MI (STEMI).

Continuous normally distributed data were described using mean (standard deviation) whereas skewed data or ordinal data were described using median (interquartile ranges). Student's t-test was used to determine significance of difference between two means, Wilcoxon's rank sum test was used to determine significance of difference between two medians, whereas the Chi-squared test (or Fisher's Exact test if value in a cell was $<5$ ) was used to determine significance of difference among count variables. All analyses were conducted using Stata V 13.0 (Statacorp, College Station, Texas, USA). A p-value of $<0.05$ was considered to be statistically significant. 
This study was approved by The Alfred Hospital Research and Ethics Committee (project number 356/16) and was conducted in accordance with the Declaration of Helsinki regarding the ethical principles for medical research involving human subjects.

\section{Results}

Over the 3 year period ( $1^{\text {st }}$ July 2013 to $30^{\text {th }}$ June 2016) 11,970 patients presenting to the emergency department had at least two troponin measurements performed within 12 hours (Figure 1). Of these 5,021 patients had an initial abnormal HsTnI result (e 16ng/L for women or e26ng/L for men) and 6,949 patients had an initial normal troponin result $(<16 \mathrm{ng} / \mathrm{L}$ for women or $<26 \mathrm{ng} / \mathrm{L}$ for men). 4172 patients had an initial HsTnI result of less than 5ng/L. 76 patients were found to have an initial very low troponin $(H \operatorname{Tn} \mathrm{T} I<5 \mathrm{ng} / \mathrm{L})$ with a subsequent serial HsTnI measurement that was abnormal. 20 of these 76 patients met the exclusion criteria -3 patients were transferred from other hospitals, 13 patients had a major trauma and 4 patients had surgery prior to the second troponin measurement.

Patient characteristics for the remaining 56 patients are outlined in Table 1 and compared to the patients with initial and subsequent normal Troponin results. Notably these 56 patients were older (mean age 61.0 vs 55.0 years), arrived more frequently by ambulance $(69.6 \%$ vs 53.4\%) and all of these patients were allocated ATS rating of 1-3 indicating that the patients were determined to require a high urgency of review on initial triage nurse assessment (Table $1)$.

Thirty-two patients with an initial HsTnI of less than 5ng/L were subsequently diagnosed with an NSTEMI (Table 2). Among this cohort the most common presenting symptoms were 
either chest pain $(n=18 ; 56.3 \%)$ or palpitations $(n=5 ; 15.6 \%) .23$ of these patients $(71.9 \%)$ had an ECG abnormality present on initial assessment. Patients diagnosed with NSTEMI frequently had risk factors for IHD present including a history of hyperlipidaemia (46.9\%), hypertension (37.5\%), or previous IHD (31.3\%).

Risk stratification scores for potential AMI were calculated (Table 2) and are based upon details in the medical record for all the included patients that had an initial $\mathrm{HsTnI}<5 \mathrm{ng} / \mathrm{L}$. All of the patients with a STEMI and $90.6 \%$ of patients with a NSTEMI had a high risk classification according to the National Heart Foundation of Australia/Cardiac Society of Australia and New Zealand (NHFA/CSANZ) 2016 Guideline for risk stratification of suspected ACS. There were no patients in this study with an initial $\operatorname{HsTnI}<5 n g / L$ and an abnormal serial troponin measurement that would have met Low risk criteria under the NHFA/CASNZ risk stratification scores. The Negative Predictive Value (NPV) of a HsTnI $<5 \mathrm{ng} / \mathrm{L}$ to exclude a diagnosis of AMI was found in this study to be $98.9 \%$ (95\% CI 98.5-99.1).

The most common discharge summary diagnosis associated with an initial $\mathrm{HsTnI}<5 \mathrm{ng} / \mathrm{L}$ and a subsequent abnormal serial HsTnI was an Acute Coronary Syndrome which was reported as the discharge diagnosis in the discharge summaries of 26 of the 56 patients (Table 3). Among the patients who met the $3^{\text {rd }}$ Universal Definition for MI in this study and were adjudicated to have a NSTEMI, there were 13 cases (40.6\%) that were diagnosed with arrhythmia at the time of discharge, and this was most frequently associated with an ECG finding of atrial fibrillation with rapid ventricular response (Table 3). There were 2 patients diagnosed with gastro-oesophageal reflux disease and one patient diagnosed with muscular chest pain 
following a cardiology admission that included negative provocative cardiac stress tests. There were 24 cases that were adjudicated by a cardiologist (WC) to be a Type I myocardial infarction, of which 15 patients were deemed to have had an STEMI and 9 patients were deemed to have had a NSTEMI. The remaining 23 patients with NSTEMI diagnosed were deemed to be Type II MI.

Only 12 patients that had an initial HsTnI of less than $5 \mathrm{ng} / \mathrm{L}$ and a diagnosis of NSTEMI underwent angiography (Table 4). 4 of the 12 patients had coronary vessel lesions that were amenable to PCI. Among the cohort there were only 2 patient deaths, both of which were in the NSTEMI cohort. One of these patients died in the context of intra-abdominal sepsis and the other had a cardiac arrest following an aspiration event.

\section{Discussion}

The findings of this investigation support the use of single very low HsTnI measurements in rapidly and safely ruling out a diagnosis of AMI in the ED among patients at low risk of IHD. A very low HsTnI was defined for this investigation as an HsTnI result of less than $5 \mathrm{ng} / \mathrm{L}$. This has recently been demonstrated to have a negative predictive value (NPV) for AMI of $99.6 \%$ (95\% CI 99.3 - 99.8) in a prospective study population presenting with chest pain to Scottish emergency departments ${ }^{12}$. In our large retrospective cohort study of 11,970 patients attending the Alfred ED over a period of 3 years we found a similar high negative predictive value of $98.9 \%$, if the initial $\mathrm{HsTnI}$ value was less than $5 \mathrm{ng} / \mathrm{L}$.

Nearly all of the patients with an initial $\mathrm{HsTnI}<5$ and a discharge diagnosis of AMI were calculated to be 'high risk' for Acute Coronary Syndrome based upon National Heart 
Foundation of Australia (NHFA/CSANZ) 2016 guidelines for risk stratification ${ }^{16}$. Based on existing national recommendations all patients who meet the NHFA/CSANZ high risk classification criteria should be referred for inpatient cardiology investigation and therefore would not have been appropriate candidates for discharge directly home from the $\mathrm{ED}^{6}$. The discharge summary diagnosis for the 3 patients with AMI that were intermediate risk were sepsis, hypertension and atrial fibrillation. All of these 3 patients had abnormal vital signs with marked tachycardias and would not have been appropriate for discharge home from the ED given their haemodynamic abnormalities during their ED presentations. All 15 patients diagnosed with STEMI with an initial $\mathrm{HsTnI}<5 \mathrm{ng} / \mathrm{L}$ also met the high risk classification due to the ST elevation on their initial ECG and should have been considered for urgent revascularisation interventions irrespective of their initial troponin result. This means that based upon risk stratification scores, none of the patients with an initial $\mathrm{HsTnI}<5 \mathrm{ng} / \mathrm{L}$ and a final diagnosis of AMI would have been eligible for direct discharge home from the ED due to their high risk classification under the National Heart Foundation of Australia risk stratification scores or their haemodynamic instability in ED. This supports the use of an accelerated protocol for potential AMI presentations that promotes rapid discharge from the ED after a single HsTnI measurement that is less than $5 \mathrm{ng} / \mathrm{L}$ in patients that are considered to be at low risk of AMI.

Our findings are in line with other contemporary research exploring the utility of HsTnI in rapidly excluding a diagnosis of AMI. The Negative Predictive Value (NPV) of a $\mathrm{HsTnI}<5 \mathrm{ng} / \mathrm{L}$ to exclude a diagnosis of AMI was found in our study to be $98.9 \%(95 \% \mathrm{CI}$ 98.5-99.1\%). This NPV agrees with the findings of Carlton, Greenslade et al. ${ }^{8}$ in which a pooled analysis of five international cohort studies determined a HsTnI cut-off of $5 \mathrm{ng} / \mathrm{L}$ had a 
NPV of 99.2\% (95\% CI 98.8-99.5\%). Similarly, Shah et al. determined a HsTnI result of less than $5 \mathrm{ng} / \mathrm{L}$ to be associated with a NPV for AMI of $99.6 \%(95 \% \text { CI } 99.3-99.8)^{12}$.

There were several potential limitations to this study. Risk stratification scores were calculated retrospectively based on documentation in the patient medical records leading to potential bias in abstracting medical records if there had been discrepancies with regard to the quality of information available in each patient record. This was a single centre study and the two investigators that performed the medical record data extraction were not blinded to patient outcomes. The adjudication of AMI was based upon reference to the $3^{\text {rd }}$ universal definition of AMI being applied to a retrospective review of the patient case by a consultant cardiologist. This study did not explore Major Adverse Cardiac Events (MACE) over a prolonged follow up period. However, analysis among a cohort of patients discharged from the ED at our centre has previously demonstrated a very low proportion of MACE ${ }^{17}$.

Despite providing supportive evidence for the efficacy of single HsTnI, the retrospective nature of this investigation does not capture the clinical outcomes that would have occurred following effective implementation of a single HsTnI threshold of less than 5ng/L for discharge decisions. Additional areas for further study would include patient outcome assessment following prospective implementation of single very low HsTnI in ED chest pain pathways, analysis of long term MACE in these patients and evaluation of the impact upon service delivery from earlier discharge of this cohort of patients with very-low initial HsTnI results.

\section{Conclusion}

This article is protected by copyright. All rights reserved. 
This study adds to the growing pool of evidence that supports the safety of future prospective studies evaluating protocols utilising rapid rule out strategies for patients presenting to the ED that are at low risk for cardiac events and have an initial HsTnI measurement of less than $5 \mathrm{ng} / \mathrm{L}$ in conjunction with robust risk assessment.

Funding: No grants or financial support were obtained for this study.

Competing interests: LB and BM are both section editors for the EMA Journal 


\section{References}

1. Zhelev Z, Hyde C, Youngman E, Rogers M, Fleming S, Slade T, Coelho H, JonesHughes T, Nikolaou V. Diagnostic accuracy of single baseline measurement of Elecsys Troponin $\mathrm{T}$ high-sensitive assay for diagnosis of acute myocardial infarction in emergency department: systematic review and meta-analysis. Bmj. 2015 Jan 21;350:h15.

2. Economics A. The economic costs of heart attack and chest pain (Acute Coronary Syndrome). Canberra: Access Economics. 2009.

3. Carlton EW, Cullen L, Than M, Gamble J, Khattab A, Greaves K. A novel diagnostic protocol to identify patients suitable for discharge after a single high-sensitivity troponin. Heart. $2015 \mathrm{Jul}$ 1;101(13):1041-6.

4. Neumann JT, Sörensen NA, Westermann D. Biomarkers in the triage of chest pain: are we making progress?. Biomarkers in Medicine. 2016;10:345-347.

5. Lippi G, Cervellin G. Cardiospecific troponin immunoassays: How low is it worth to go?. European journal of internal medicine. 2016 May 1;30:e7-8.

6. Cullen L, Greenslade J, Merollini K, Graves N, Hammett CJ, Hawkins T, Than MP, Brown AF, Huang CB, Panahi SE, Dalton E. Cost and outcomes of assessing patients with chest pain in an Australian emergency department. Med J Aust. 2015 May 4;202(8):427-32. 
7. Bandstein N, Ljung R, Johansson M, Holzmann MJ. Undetectable high-sensitivity cardiac troponin $\mathrm{T}$ level in the emergency department and risk of myocardial infarction. Journal of the American College of Cardiology. 2014 Jun 17;63(23):256978.

8. Carlton EW, Khattab A, Greaves K. Identifying patients suitable for discharge after a single-presentation high-sensitivity troponin result: a comparison of five established risk scores and two high-sensitivity assays. Annals of emergency medicine. $2015 \mathrm{Dec}$ 31;66(6):635-45.

9. Mueller C, Giannitsis E, Möckel M, Huber K, Mair J, Plebani M, Thygesen K, Jaffe AS, Lindahl B. Rapid rule out of acute myocardial infarction: novel biomarker-based strategies. European Heart Journal: Acute Cardiovascular Care. 2016 Jul $1: 2048872616653229$

10. Carlton E, Greenslade J, Cullen L, Body R, Than M, Pickering JW, Aldous S, Carley S, Hammett C, Kendall J, Keevil B. Evaluation of high-sensitivity cardiac troponin I levels in patients with suspected acute coronary syndrome. Jama cardiology. $2016 \mathrm{Jul}$ $1 ; 1(4): 405-12$.

11. Bain C, Mac Manus C, Seah J. Web Based Cohort Identification across Large Healthcare Data Sets-Opening the Treasure Chest. InProceedings of the International Conference on Computer Science, Data Mining and Mechanical EngineeringICCDMME 2015

12. Shah AS, Anand A, Sandoval Y, Lee KK, Smith SW, Adamson PD, Chapman AR, Langdon T, Sandeman D, Vaswani A, Strachan FE. High-sensitivity cardiac troponin 
I at presentation in patients with suspected acute coronary syndrome: a cohort study. The Lancet. 2016 Jan 1;386(10012):2481-8.

13. Trambas C, Pickering JW, Than M, Bain C, Nie L, Paul E, Dart A, Broughton A, Schneider HG. Impact of high-sensitivity troponin I testing with sex-specific cutoffs on the diagnosis of acute myocardial infarction. Clinical chemistry. 2016 Jun $1 ; 62(6): 831-8$

14. Cullen L, Greenslade JH, Carlton EW, Than M, Pickering JW, Ho A, Greaves K, Berndt SL, Body R, Ryan K, Parsonage WA. Sex-specific versus overall cut points for a high sensitivity troponin I assay in predicting 1-year outcomes in emergency patients presenting with chest pain. Heart. 2016 Jan 15;102(2):120-6.

15. Thygesen K, Alpert JS, Jaffe AS, Simoons ML, Chaitman BR, White HD, Writing Group on behalf of the Joint ESC/ACCF/AHA/WHF Task Force for the Universal Definition of Myocardial Infarction, Authors/Task Force Members Chairpersons, Thygesen K, Alpert JS, White HD. Third universal definition of myocardial infarction. European heart journal. 2012 Aug 24;33(20):2551-67.

16. Chew DP, Scott IA, Cullen L, French JK, Briffa TG, Tideman PA, Woodruffe S, Kerr A, Branagan M, Aylward PE. National Heart Foundation of Australia and Cardiac Society of Australia and New Zealand: Australian clinical guidelines for the management of acute coronary syndromes 2016. Med J Aust. 2016 Aug 1;205(3):128-33.

17. Rahman F, Mitra B, Cameron PA, Coleridge J. Stress testing before discharge is not required for patients with low and intermediate risk of acute coronary syndrome after 
emergency department short stay assessment. Emergency Medicine Australasia. 2010

Oct 1;22(5):449-56.

Tables

Table 1. Demographics for all patients with an initial HsTnI $<5 \mathrm{ng} / \mathrm{L}$

\begin{tabular}{|l|l|l|l|}
\hline & $\begin{array}{l}\text { Initial HsTnI } \\
\text { <5ng/L with } \\
\text { normal serial } \\
\text { HsTnI } \\
\text { measurement. } \\
\mathrm{n}=4096\end{array}$ & $\begin{array}{l}\text { Initial HsTnI } \\
\text { <5ng/L with } \\
\text { abnormal serial } \\
\text { HsTnI } \\
\text { measurement } \\
\text { that met } \\
\text { inclusion } \\
\text { criteria } \\
\mathrm{n}=56\end{array}$ & p-value \\
\hline Age, mean years (SD) & $55.0(16)$ & $61(15)$ & 0.006 \\
\hline Sex, $\mathrm{n}(\%)$ & & 0.06 \\
\hline Male & $2270(55.4)$ & $38(67.9)$ & \\
\hline Female & $1826(44.6)$ & $18(32.1)$ & \\
\hline Triage Category, $\mathrm{n}(\%)$ & & $4(7.1)$ & $<0.01$ \\
\hline 1 & $37(0.9)$ & $43(76.8)$ & \\
\hline 2 & $1815(44.3)$ & & \\
\hline
\end{tabular}

This article is protected by copyright. All rights reserved. 


\begin{tabular}{|c|c|c|c|}
\hline 3 & $2000(48.8)$ & $9(16.1)$ & \\
\hline 4 & $238(5.8)$ & $0(0.0)$ & \\
\hline 5 & $6(0.1)$ & $0(0.0)$ & \\
\hline \multicolumn{4}{|l|}{ Mode of Transport, $\mathrm{n}(\%)$} \\
\hline - Road Ambulance & $2189(53.4)$ & $39(69.6)$ & 0.40 \\
\hline $\begin{array}{l}\text { - Private Car/public } \\
\text { transport }\end{array}$ & $1852(45.2)$ & $17(30.4)$ & \\
\hline $\begin{array}{l}\text { - Helicopter/air } \\
\text { ambulance }\end{array}$ & $47(1.1)$ & $0(0.0)$ & \\
\hline - $\quad$ Other (police/unknown) & $8(0.2)$ & $0(0.0)$ & \\
\hline \multicolumn{4}{|l|}{ Time Measures } \\
\hline $\begin{array}{l}\text { Time from ED Arrival to first } \\
\text { troponin measurement, median } \\
\text { minutes (Interquartile Range) }\end{array}$ & $43(29-66)$ & $22(13-34)$ & $<0.01$ \\
\hline $\begin{array}{l}\text { Time from ED arrival to second } \\
\text { troponin measurement, median } \\
\text { minutes (Interquartile Range) }\end{array}$ & $301(228-399)$ & $379(294-462)$ & $<0.01$ \\
\hline $\begin{array}{l}\text { Time interval between first and } \\
\text { second troponin measurements, } \\
\text { median minutes (Interquartile } \\
\text { Range) }\end{array}$ & $245(180-350)$ & $371(256-424)$ & $<0.01$ \\
\hline $\begin{array}{l}\text { ED LOS, median minutes } \\
\text { (Interquartile Range) }\end{array}$ & $180(115-234)$ & $181(85.8-307.8)$ & 0.79 \\
\hline \multicolumn{4}{|l|}{ Pathology } \\
\hline $\begin{array}{l}\text { Initial HsTnI measurement, } \\
\text { mean ng/L (SD) }\end{array}$ & $2.5(0.7)$ & $3.2(0.8)$ & $<0.01$ \\
\hline $\begin{array}{l}\text { Serial HsTnI measurement, } \\
\text { mean ng/L (SD) }\end{array}$ & $2.9(1.8)$ & $\begin{array}{l}5442.6 \\
(15554.5)\end{array}$ & $<0.01$ \\
\hline eGFR, mean mmol/L (SD) & $81.0(13.7)$ & $76.3(13.7)$ & 0.010 \\
\hline
\end{tabular}


Table 2. Features of patient presentations in which there was an initial HsTnI $<5 \mathrm{ng} / \mathrm{L}$ and elevated serial HsTnI result

\begin{tabular}{|c|c|c|c|c|}
\hline & $\begin{array}{l}\text { STEMI } \\
\text { Diagnosis } \\
\mathrm{n}=15\end{array}$ & $\begin{array}{l}\text { NSTEMI } \\
\text { Diagnosis } \\
\mathrm{n}=32\end{array}$ & $\begin{array}{l}\text { No Diagnosis of } \\
\text { AMI } \\
\mathrm{n}=9\end{array}$ & p-value* \\
\hline \multicolumn{5}{|l|}{$\begin{array}{l}\text { Presenting } \\
\text { Symptom, n (\%) }\end{array}$} \\
\hline Chest Pain & $11(73.3)$ & $18(56.3)$ & $4(44.4)$ & 0.63 \\
\hline Palpitations & $0(0.0)$ & $5(15.6)$ & $0(0.0)$ & 0.60 \\
\hline Syncope/pre-syncope & $0(0.0)$ & $4(12.5)$ & $1(11.1)$ & 0.70 \\
\hline Cardiac Arrest & $2(13.3)$ & $2(6.3)$ & $1(11.1)$ & 0.53 \\
\hline Dyspnoea & $1(6.7)$ & $1(3.1)$ & $0(0.0)$ & 0.78 \\
\hline Abdominal Pain & $0(0.0)$ & $1(3.1)$ & $0(0.0)$ & 0.78 \\
\hline Poisoning & $0(0.0)$ & $1(3.1)$ & $1(11.1)$ & 0.40 \\
\hline $\begin{array}{l}\text { Febrile } \\
\text { illness/hypothermia }\end{array}$ & $0(0.0)$ & $0(0.0)$ & $1(11.1)$ & 0.22 \\
\hline Vomiting & $0(0.0)$ & $0(0.0)$ & $1(11.1)$ & 0.22 \\
\hline Back Pain & $1(6.7)$ & $0(0.0)$ & $0(0.0)$ & - \\
\hline \multicolumn{5}{|l|}{ ECG, n (\%) } \\
\hline $\begin{array}{l}\text { No new ECG } \\
\text { abnormality }\end{array}$ & $1(6.7)$ & $8(25.0)$ & $5(55.6)$ & 0.11 \\
\hline $\begin{array}{l}\text { ST segment } \\
\text { elevation }\end{array}$ & $14(93.3)$ & $1(3.1)$ & $0(0.0)$ & 0.78 \\
\hline $\begin{array}{l}\text { Atrial } \\
\text { Fibrillation/Atrial } \\
\text { flutter }\end{array}$ & $0(0.0)$ & 7 (21.9) & $2(22.2)$ & 0.99 \\
\hline $\begin{array}{l}\text { ST segment } \\
\text { depression/flattening } \\
\text { and/or T wave } \\
\text { inversion }\end{array}$ & $0(0.0)$ & $10(31.3)$ & $0(0.0)$ & 0.08 \\
\hline Sinus tachycardia & $0(0.0)$ & $4(12.5)$ & $2(22.2)$ & 0.60 \\
\hline Sinus bradycardia & $0(0.0)$ & $1(3.1)$ & $0(0.0)$ & 0.78 \\
\hline
\end{tabular}




\begin{tabular}{|c|c|c|c|c|}
\hline ECG not available & $0(0.0)$ & $1(3.1)$ & $0(0.0)$ & 0.78 \\
\hline \multicolumn{5}{|l|}{$\begin{array}{l}\text { Comorbidities, } \mathrm{n} \\
(\%)\end{array}$} \\
\hline $\begin{array}{l}\text { Pre-existing } \\
\text { Ischaemic Heart } \\
\text { Disease (IHD) }\end{array}$ & $3(20.0)$ & $10(31.3)$ & $1(11.1)$ & 0.40 \\
\hline Hypertension & $7(46.7)$ & $12(37.5)$ & $4(44.4)$ & 0.72 \\
\hline Hyperlipidaemia & $8(53.3)$ & $15(46.9)$ & $5(55.6)$ & 0.72 \\
\hline Previous smoker & $746.7)$ & $12(37.5)$ & $1(11.1)$ & 0.23 \\
\hline Diabetes Mellitus & $5(33.3)$ & $3(9.4)$ & $1(11.1)$ & 0.99 \\
\hline $\begin{array}{l}\text { Family History of } \\
\text { IHD }\end{array}$ & $3(9.4)$ & $7(21.9)$ & $1(11.1)$ & 0.66 \\
\hline Obesity & $5(15.6)$ & $2(6.3)$ & $1(11.1)$ & 0.53 \\
\hline \multicolumn{5}{|l|}{$\begin{array}{l}\text { NHFA/CSANZ } \\
\text { 2016 Risk } \\
\text { Stratification }{ }^{<}, n \\
(\%)\end{array}$} \\
\hline High Risk & $15(100.0)$ & $29(90.6)$ & $6(66.7)$ & 0.11 \\
\hline Intermediate Risk & $0(0.0)$ & $3(9.4)$ & $3(33.3)$ & 0.11 \\
\hline Low Risk & $0(0.0)$ & $0(0.0)$ & $0(0.0)$ & - \\
\hline
\end{tabular}

NHFA/CSANZ: The National Heart Foundation of Australia and Cardiac Society of Australia and New Zealand (2016 Guideline)

*Compares patients diagnosed with NSTEMI to patients with no diagnosis of AMI 
Table 3. Discharge summary diagnosis patient presentations in which there was an initial $\mathrm{HsTnI}<5 \mathrm{ng} / \mathrm{L}$ and elevated

\begin{tabular}{|l|l|l|l|l|}
\hline & $\begin{array}{l}\text { STEMI } \\
\text { Diagnosis } \\
\mathrm{n}=15\end{array}$ & $\begin{array}{l}\text { NSTEMI } \\
\text { Diagnosis } \\
\mathrm{n}=32\end{array}$ & $\begin{array}{l}\text { No Diagnosis of } \\
\text { AMI } \\
\mathrm{n}=9\end{array}$ & p-value* \\
\hline $\begin{array}{l}\text { Discharge summary } \\
\text { diagnosis, n (\%) }\end{array}$ & $15(100.0)$ & $11(34.4)$ & $0(0.0)$ & $<0.01$ \\
\hline $\begin{array}{l}\text { Acute Coronary } \\
\text { Syndrome }\end{array}$ & $0(0.0)$ & $13(40.6)$ & $0(0.0)$ & \\
\hline Arrhythmia & $0(0.0)$ & $4(12.5)$ & $2(22.2)$ & \\
\hline Infection & $0(0.0)$ & $2(6.3)$ & $0(0.0)$ & \\
\hline Myocarditis & $0(0.0)$ & $1(3.1)$ & $0(0.0)$ & \\
\hline Hypertension & $0(0.0)$ & $1(3.1)$ & $0(0.0)$ & \\
\hline Hypoxia & $0(0.0)$ & $0(0.0)$ & $1(11.1)$ & \\
\hline Vasovagal syncope & $0(0.0)$ & $0(0.0)$ & $2(22.2)$ & \\
\hline Overdose/Poisoning & $0(0.0)$ & $0(0.0)$ & $1(11.1)$ & \\
\hline Anaphylaxis & $0(0.0)$ & $0(0.0)$ & $2(22.2)$ & $1(11.1)$ \\
\hline GORD & $0(0.0)$ & $0(0.0)$ & & \\
\hline Muscular pain & $0.0)$ & \\
\hline
\end{tabular}

* Compares patients with NSTEMI to those with no diagnosis of AMI 
Table 4. Outcomes for patient presentations in which there was an initial $\mathrm{HsTnI}<5 \mathrm{ng} / \mathrm{L}$ and an abnormal serial HsTnI result

\begin{tabular}{|c|c|c|c|c|}
\hline & $\begin{array}{l}\text { STEMI } \\
\text { Diagnosis } \\
\mathrm{n}=15\end{array}$ & $\begin{array}{l}\text { NSTEMI } \\
\text { Diagnosis } \\
\mathrm{n}=32\end{array}$ & $\begin{array}{l}\text { No Diagnosis } \\
\text { of AMI } \\
n=9\end{array}$ & p-value* \\
\hline 30 day survival, $n(\%)$ & & & & 0.26 \\
\hline Survived & $15(100)$ & $30(93.8)$ & $8(88.9)$ & \\
\hline Deceased & $0(0.0)$ & $2(6.2)$ & $0(0.0)$ & \\
\hline Unknown & $0(0.0)$ & $0(0.0)$ & $1(11.1)$ & \\
\hline $\begin{array}{l}\text { Provocative Stress } \\
\text { Testing Outcome, } \mathrm{n}(\%)\end{array}$ & & & & 0.47 \\
\hline $\begin{array}{l}\text { Provocative stress test } \\
\text { positive }\end{array}$ & $0(0.0)$ & $1(3.1)$ & $0(0.0)$ & \\
\hline $\begin{array}{l}\text { Provocative stress test } \\
\text { negative }\end{array}$ & $0(0.0)$ & $4(12.5)$ & $3(33.3)$ & \\
\hline $\begin{array}{l}\text { Provocative stress test } \\
\text { not performed }\end{array}$ & $15(100.0)$ & $27(84.4)$ & $6(66.7)$ & \\
\hline Angiogram, n (\%) & & & & $<0.01$ \\
\hline Angiogram Performed & $15(100.0)$ & $12(37.5)$ & $0(0.0)$ & \\
\hline 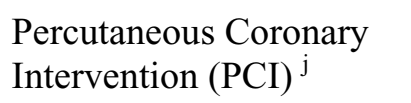 & $14(93.3)$ & $4(12.5)$ & $0(0.0)$ & \\
\hline
\end{tabular}




\begin{tabular}{|l|l|l|l|l|}
\hline CABG & $1(6.7)$ & $0(0.0)$ & $0(0.0)$ & \\
\hline Medical Management & $0(0.0)$ & $8(25.0)$ & $0(0.0)$ & \\
\hline Medication, $\mathrm{n}(\%)$ & & & 0.002 \\
\hline $\begin{array}{l}\text { Antiplatelet or } \\
\text { Anticoagulant therapy } \\
\text { discharge medication }\end{array}$ & $15(100.0)$ & $18(56.3)$ & $0(0.0)$ & \\
\hline
\end{tabular}

${ }^{j}$ PCI refers to the installation of either a Bare Metal Stent (BMS) or Drug Eluding Stent (DES) following angiography

${ }^{\S}$ Medical management refers to patients who underwent an angiogram but did not receive a $\mathrm{PCI} / \mathrm{CABG}$ and instead were treated with plan for optimisation of treatment for cardiac risk factors.

* Compares patients with NSTEMI with those with no diagnosis of AMI 
Figure 1. Patients that had undergone serial troponin measurements that met predefined study inclusion criteria.

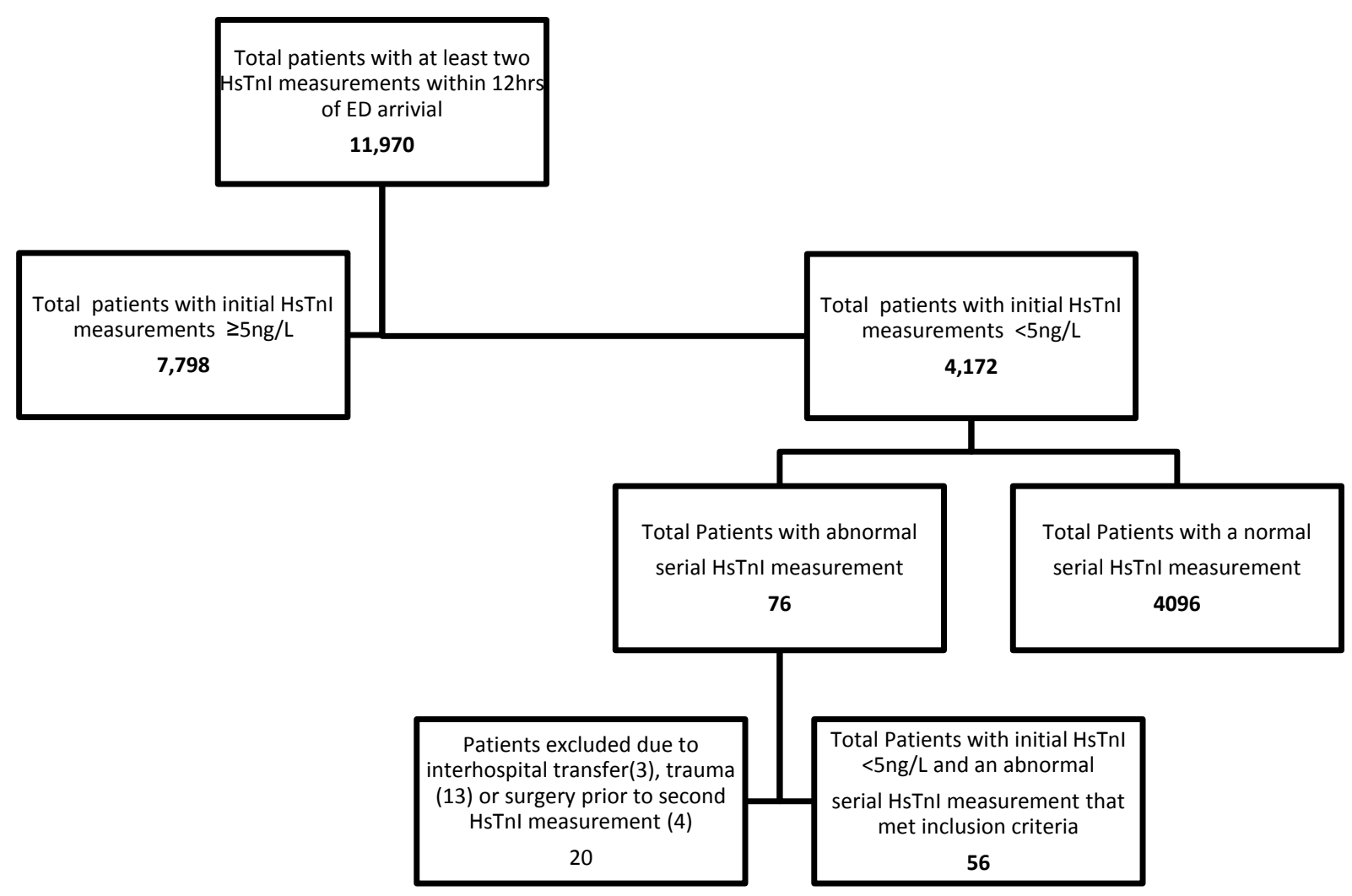




\section{University Library}

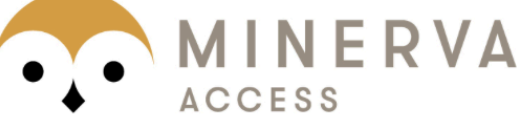

A gateway to Melbourne's research publications

Minerva Access is the Institutional Repository of The University of Melbourne

Author/s:

Brichko, L;Schneider, HG;Chan, W;Seah, J;Smit, DV;Dart, A;Stevens, JP;Mitra, B

Title:

Rapid and safe discharge from the emergency department: A single troponin to exclude acute myocardial infarction

Date:

2018-08-01

Citation:

Brichko, L., Schneider, H. G., Chan, W., Seah, J., Smit, D. V., Dart, A., Stevens, J. P. \& Mitra, B. (2018). Rapid and safe discharge from the emergency department: A single troponin to exclude acute myocardial infarction. EMERGENCY MEDICINE AUSTRALASIA, 30 (4), pp.486-493. https://doi.org/10.1111/1742-6723.12919.

Persistent Link:

http://hdl.handle.net/11343/283477 